\title{
MEMBANGUN MENTAL WIRAUSAHA UNTUK MENINGKATKAN TARAF HIDUP MASYARAKAT RT 006 RW 10 KP CIMUNCANG DESA KARANGNUNGGAL KABUPATEN TASIKMALAYA PROPINSI JAWA BARAT
}

\author{
Purwanti, Destian Andhani, Ria Roslia Simangunsong, Mitri Nelsi, Siska Yunanti \\ Universitas Pamulang \\ Email: dosen02578@unpam.ac.id
}

\begin{abstract}
The natural resources owned by the Indonesian state must be managed properly so that the benefits can be felt by all Indonesian people. This is in accordance with what is mandated in the 1945 Constitution Article 33 Paragraph 1 to Paragraph 5 concerning the principles of the Indonesian economy and the management of the country's natural wealth. The success of natural resource management cannot be separated from human resources as the driving force, managing the natural resources owned. Thus, it is necessary to increase superior human resources (human resources) to be able to manage natural resources (natural resources) so that the benefits can be felt by all Indonesian people. This can be done by doing entrepreneurship to improve the standard of living of the community itself. Optimization of agricultural products can be done by means of good processing so as to add to the aesthetic value of these products. The application of agricultural product processing techniques is a solution to these problems. One way to improve the welfare of farmers is by providing reliable agricultural processing technology that can increase the economic value of agricultural products. The community of RT $006 \mathrm{Rw} 10$ in Cimuncang village, most of whom live by farming or cultivating crops which are currently still experiencing obstacles to be able to maximize their business results and the lack of business mentality which impacts on the income of rural farmers and breeders that fluctuates according to market conditions and nature, so that it contributes the largest number of poverty, and it is difficult to raise the standard of living of the community RT 006 RW 10 Kp Cimuncang, Karangnunggal Village, Tasikmalaya Regency, West Java Province. Based on this problem, we, from the Community Service Program (PKM) Team of Pamulang University (UNPAM), totaling 5 lecturers, are called to participate to help solve problems faced by the community by providing counseling on business mentality to increase public awareness about the importance of entrepreneurship among them to reduce unemployment. and improve the standard of living of the people of RT 006 RW $10 \mathrm{Kp}$ Cimuncang, Karangnunggal Village, Tasikmalaya Regency, West Java Province. The target output that we will achieve is so that residents of RT 006 / RW 10, Cimuncang Village, Karangnunggal Village, Tasikmalaya, West Java can find out how to increase income by processing agricultural products.
\end{abstract}

Keywords: Entrepreneurial Mental and Standard of Living 
Kekayaan alam yang dimiliki oleh negara Indonesia harus dikelola dengan baik sehingga manfaatnya dapat dirasakan oleh seluruh rakyat Indonesia. Hal ini sesuai dengan apa yang diamanatkan dalam Undang - Undang Dasar tahun 1945 Pasal 33 Ayat 1 sampai dengan ayat 5 tentang prinsip ekonomi Indonesia serta pengelolaan kekayaan alam negara. Keberhasilan pengelolaan sumber daya alam tidak terlepas dari sumber daya manusia sebagai penggerak, pengelola sumber daya alam yang dimiliki. Dengan demikian, perlu adanya peningkatan SDM (sumber daya manusia) yang unggul untuk dapat mengelola SDA (sumber daya alam) agar manfaatnya dapat dirasakan oleh seluruh rakyat Indonesia. Hal tersebut dapat dilakukan dengan berwirausaha untuk menaikan taraf hidup masyarkat itu sendiri. Pengoptimalan hasil pertanian dapat dilakukan dengan cara pengolahan yang baik sehingga menambah nilai estetika dari produk tersebut. Aplikasi teknik pengolahan hasil pertanian adalah solusi untuk permasalahan tersebut. Salah satu cara meningkatkan kesejahteraan petani adalah dengan menyediakan teknologi pengolahan hasil pertanian yang handal yang mampu meningkatkan nilai ekonomis hasil pertanian. Masyarakat RT 006 Rw 10 kampung Cimuncang, sebagian besar hidup dengan bertani atau bercocok tanam yang saat ini masih mengalami kendala untuk bisa memaksimalkan hasil usaha mereka dan minimnya mental usaha yang berimbas dengan pendapatan petani dan peternak perdesaan fluktuatif sesuai keadaan pasar dan alam, sehingga memberikan kontribusi terbesar angka kemiskinan, dan sulit untuk menaikan taraf hidup masyarakat RT 006 RW $10 \mathrm{Kp}$ Cimuncang Desa Karangnunggal Kabupaten Tasikmalaya Propinsi Jawa Barat. Berdasarkan permasalahan ini kami dari Tim Program Pengabdian Masyarakat (PKM) Universitas Pamulang (UNPAM) yang berjumlah 5 dosen terpanggil untuk ikut serta membantu memecahkan persoalan yang dihadapi oleh masyarakat dengan melakukan penyuluhan tentang mental usaha untuk meningkatkan kesadaran masyarakat tentang pentingnya berwirausaha diantara nya untuk mengurangi pengangguran dan meningkatkan taraf hidup masyarakat RT 006 RW 10 Kp Cimuncang Desa Karangnunggal Kabupaten Tasikmalaya Propinsi Jawa Barat. Target luaran yang kami akan capai adalah agar Warga RT 006/RW 10, Kampung Cimuncang, Desa Karangnunggal, Tasikmalaya, Jawa Barat dapat mengetahui bagaimana cara meningkatkan pendapatan dengan mengolah hasil pertanian.

Kata Kunci : Mental Wirausaha dan Taraf Hidup

\section{A. PENDAHULUAN}

Kekayaan alam yang dimiliki oleh negara Indonesia harus dikelola dengan baik sehingga manfaatnya dapat dirasakan oleh seluruh rakyat Indonesia. Hal ini sesuai dengan apa yang diamanatkan dalam Undang - Undang Dasar tahun 1945 Pasal 33 Ayat 1 sampai dengan ayat 5 tentang prinsip ekonomi Indonesia serta pengelolaan kekayaan alam negara. Keberhasilan pengelolaan sumber daya alam tidak terlepas dari sumber daya manusia sebagai penggerak, pengelola sumber daya alam yang dimiliki. Dengan demikian, perlu adanya 
peningkatan SDM (sumber daya manusia) yang unggul untuk dapat mengelola SDA (sumber daya alam) agar manfaatnya dapat dirasakan oleh seluruh rakyat Indonesia. Hal tersebut dapat dilakukan dengan berwirausaha untuk menaikan taraf hidup masyarkat itu sendiri.

Sebelum kita memahami akan konsep mental wirausaha. Alangkah baiknya kita ulas pengertian dari wirausaha. Secara sederhana arti wirausahawan (entrepreneur) adalah orang yang berjiwa berani mengambil resiko untuk membuka usaha dalam berbagai kesempatan. Berjiwa berani mengambil resiko artinya bermental mandiri dan berani memulai usaha tanpa diliputi rasa takut atau cemas sekalipun dalam kondisi tidak pasti. Kegiatan wirausaha dapat dilakukan seorang diri atau berkelompok. Seorang wirausahawan dalam pemikirannya selalu berusaha mencari, memanfaatkan, serta menciptakan peluang usaha yang dapat memberikan keuntungan. Resiko kerugian merupakan hal yang biasa karena mereka memegang prinsip bahwa faktor kerugian pasti ada. Bahkan, semakin besar resiko kerugian yang bakal dihadapi, semakin besar pula peluang keuntungan yang diraih. Tidak ada istilah rugi selama seseorang melakukan usaha dengan penuh keberanian dan penuh perhitungan. Inilah yang disebut dengan jiwa wirausaha.

Ekonom Perancis, J.B say, menciptakan kata entrepreneur (wirausahawan) sekitar tahun 1800 "Wirausahawan menggeser sumber daya ekonomi dari bidang produktifitas yang lebih rendah ke bidang yang lebih tinggi dan hasil yang lebih besar" (Armstrong, 2003:149). Keberhasilan seorang wirausaha untuk mengembangkan bisnisnya tergantung pada kecerdasan, imajinasi, dan kekuatan keinginan individu yang bersangkutan. Sedikit keberuntungan diperlukan, tetapi dapat diargumentasikan bahwa tidak ada keberuntungan mengubah visi menjadi realita lebih berupa kerja keras, di samping imajinasi dan kemampuan yang mampu merubah karir individu menjadi sukses.

Menjadi seorang wirausahawan berarti memadukan sikap pribadi, keuangan, dan sumber daya yang ada disekitar kita. Setiap wirausahawan memiliki sikap yang unik dan memiliki gaya tersendiri dalam mengelola usahanya. Oleh karena itu, dalam berwirausaha tidak hanya mengandalkan modal, baik berupa uang atapun sumber daya alam, namun dalam berwirausaha kita juga harus memiliki modal dalam bentuk dikap dan kepribadian. (Rachbini, 2001:100) Sikap mental merupakan elemen paling dasar yang perlu dijamin untuk selalu dalam keadaan baik. Unsur ini yang menentukan apakah seseorang menjadi sosok yang tinggi budi ataukah sebaliknya menjadi orang yang jahat dan culas. Oleh karena itu, pentingnya pembinaan sikap dan mental menjadi unsur terpenting dalam dunia wirausaha. Selain menghadirkan sifat-sifat baik alamiah seperti kejujuran dan ketulusan, sikap mental mencakup juga segi-segi positif dalam hal motivasi dan proaktif.

Manusia yang bersikap mental wirausaha memiliki keyakinan yang kuat atas kekuatan yang ada pada dirinya. Kita lahir di dunia telah dibekali dengan perlengkapan dan kekuatan sang pencipta agar kita dapat hidup dan menaklukan alam sekitar kita. Keyakinan inilah yang memberikan harapan, kegairahan serta semangat untuk bekerja atau berbuat kea rah tercapainya tujuan-tujuan hidup kita. Bagaimana menimbulkan kenyataan yang kuat dalam hidup kita? Ingat bahwa yang dimaksud dengan keyakinan kuat di sini dapat disamakan dengan fanatisme dalam sikap dan pendangan hidup seseorang. Keyakinan yang kuat dapat kita tumbuhkan di dalam jiwa kita dengan syarat: 
1. Kita harus mengenal diri kita sendiri sebagai makhluk yang memiliki kelemahan, namun memperoleh anugerah kekuatan dari Yang Maha Kuasa untuk mengatasi kelemahan kita itu.

2. Kita harus percaya kepada kemampuan diri sendiri, bahwa kita memiliki potensi tersendiri yang tidak kurang kuatnya dengan apa yang dimiliki oleh orang lain. Coba renungkan, kalau orang lain bias mencapai kesuksesan, mengapa kita tidak bisa?

3. Kita harus mengetahui dengan jelas terhadap tujuan-tujuan serta kebutuhan kita, dimana kita dapat mendapatkannya, bagaimana cara-cara untuk mencapai atau memenuhinya, serta kapan/beberapa lama target waktu untuk mencapai/memenuhinya, serta Setiap tujuan, kebutuhan dan rencana-rencana kita harus senantiasa menguasai jiwa kita dengan penuh kesabaran. Hal ini akan menumbuhkan kepercayaan kepada diri sendiri, sehingga dengan demikian timbul pula kegairahan dan semangat untuk maju dan kita terdorong dan tergerak untuk berbuat.

Seorang wirausahawan penting mempunyai visi dan misi di lini usahanya. Hal ini merupakan kekuatan atau daya ampuh baik dalam perencanaan, pengorganisasian, penggerakan, pengawasan, personality, pengarahan, pelaporan, efesiensi (dana). Berarti ada suatu sinergi dalam usaha karakteristik kewirausahaan, yaitu sebagai berikut :

1. Cita-cita untuk maju Visi dan Misi menunjukkan sikap pribadi yang optimis dalam melihat suatu peluang yang berorientasi secara strategik dalam meraih visi dan misi dengan daya kemampuan yang kuat, yaitu: Berani menentukan resiko dalam sukses dan berfikir positif.

2. Percaya diri Dorongan dari dalam diri sendiri tanpa menghiraukan pengaruh luar yang subjektif. Orentasi tertuju keluar, fikiran, perasan serta tindakan obyektif. Yakin akan kemampuan, kecerdasan, keahlian, selalu membangkitkan optimisme dalam mencari jalan keluar pada dampak hambatan yang bervariasi.

3. Kuat dan Tahan Mental Dalam interaksi usaha, lingkungan adalah gelombang yang harus di tahan. Misal ada dua system ombak lingkungan yaitu longitudinal dan transversal. Wirausahawan sebagai sebuah bentuk konstruksi kapal yang mampu berhadapan dengan kedua ombak tersebut. Di mana untuk menikmati keberhasilan dalam usaha terbentang hambatan dan godaan. Normalnya wirausahawan secara luhur bertaqwa kepada Tuhan Yang Maha Esa.

4. Naluri dan Intuisi yang Tajam Wirausahawan adalah figur, inovator bukan plagiator, figure pemimpin bukan pengekor. Ketajaman naluri dan intuisi selalu berproses sebagai latihan dan pengalaman sehingga selalu terbuka peluang bisnis.

Masyarakat RT 006 RW 10 kampung Cimuncang, sebagian besar hidup dengan bertani atau bercocok tanam yang saat ini masih mengalami kendala untuk bisa memaksimalkan hasil usaha mereka dan minimnya mental usaha yang berimbas dengan pendapatan petani di perdesaan fluktuatif sesuai keadaan pasar dan alam, sehingga memberikan kontribusi terbesar angka kemiskinan, dan sulit untuk menaikan taraf hidup masyarakat RT 006 RW 10 Kampung Cimuncang Desa Karangnunggal Kabupaten Tasikmalaya Propinsi Jawa Barat. Kurang pahamnya masyarakat dengan adanya mental usaha dan ilmu berwirausaha sehingga masyarakat itu sendiri belum bisa mengoptimalkan nilai jual hasil pertanian dan kebun mereka. Apabila hasil pertanian masyarakat kampung cimuncang dapat diolah menjadi berbagai macam makanan, sehingga menciptakan nilai lebih, dibandingkan mereka langsung menjualnya kepada pengepul dalam bentuk hasil pertanian dan peternakan tersebut tanpa diolah terlebih dahulu.

Pengoptimalan hasil pertanian dapat dilakukan dengan cara pengolahan yang baik sehingga menambah nilai estetika dari produk tersebut. Aplikasi teknik pengolahan hasil pertanian adalah solusi untuk permasalahan tersebut. Salah satu cara meningkatkan 
kesejahteraan petani adalah dengan menanamkan kesadaran akan wirausaha dengan menyediakan teknologi pengolahan hasil pertanian yang handal yang mampu meningkatkan nilai ekonomis hasil pertanian

\section{B. METODE PELAKSANAAN KEGIATAN}

Metode dalam pelaksanaan pelatihan adalah cara yang digunakan untuk mengimplementasikan rencana yang sudah disusun dalam kegiatan nyata agar tujuan yang telah disusun tercapai secara optimal. Berikut beberapa metode pelatihan yang biasa digunakan pada saat proses pelatihan berlangsung. Metode Ceramah Metode ceramah merupakan metode yang sampai saat ini sering digunakan oleh setiap pelatih. Metode Demontrasi merupakan salah satu metode yang cukup efektif dalam proses pelatihan, karena dapat membantu siswa untuk mencari jawaban dengan usaha sendiri berdasarkan fakta atau data yang benar.

Dokumentasi adalah suatu metode untuk mencari data variabel yang berupa catatancatatan penting, transkrip nilai, buku, prasasti dan sebagainya (Suharsimi Arikunto 2006:130). Metode pelaksanaan yang digunakan pada program kegiatan ini diharapkan dapat memberikan kemudahan kepada masyarakat. Dalam kegiatan ini, metode yang digunakan adalah metode penjelasan, sharing, tanya jawab, diskusi dan praktek. Pada metode penjelasan, setiap instruktur menyampaikan materi terkait dan membuat tampilan visual berupa slide power point yang ditampilkan ke layar dengan alat LCD proyektor.

Dalam penyuluhan ini, nara sumber berfokus kepada masyarakat Kp. Cimuncang, Desa Karangnunggal, Kecamatan Karangnunggal, Kabupaten Tasikmalaya, Jawa Barat. Dimana strategi ini dipilih karena era saat ini adalah era persaingan bebas, dimana pengarahan dan penyuluhan kepada masyarakat diperlukan dalam menumbuhkan semangat untuk berwirausaha guna meningkatkan taraf hidup Masyarakat Rt 006 Rw 10 Kp Cimuncang Desa Karangnunggal Kabupaten Tasikmalaya Propinsi Jawa Barat. Nara sumber dalam menyampaikan penjelasan juga memasukkan unsur "sharing" atau berbagi pengalaman mengenai pengolahan hasil pertanian menjadi berbagai macam produk yang akan dipasarkan dan memiliki nilai jual.

\section{HASIL DAN PEMBAHASAN}

Desa Karangnunggal dibentuk sejak zaman penjajahan Belanda, dan diberi nama Karangnunggal yang diambil dari nama sebuah kandungan air laut yakni: Karang, Karang adalah jenis batu-batuan di laut yang mempunyai kekuatan dan mampu bertahan di terjang ombak (dalam bahasa sunda Bedas). Nunggal adalah asal kata dari tunggal yang berarti satu (Bersatu). Dengan dinamakan Karangnunggal mempunyai sebuah harapan yang sangat berharga bahwa masyarakat Desa Karangnunggal akan mampu mempererat hubungan persaudaraan, meningkatnya persatuan dan kesatuan dalam mempertahankan segala macam tantangan dan hambatan dari segala aspek 23 yaitu Ideologi, Poltik, Ekonomi, Sosial, Budaya dan Pertahanan Kemanan rakyat semesta.

Masyarakat RT 006 RW $10 \mathrm{Kp}$. Cimuncang adalah masyarakat yang dengan aktivitas pekerjaan sehari sehari sebagai petani yang dengan giat berusaha untuk dapat meningkatkan taraf hidup mereka, maka sudah sewajarnya kami juga membantu mereka agar dapat meningkatkan pendapatan penjualan dari hasil pertanian dengan memberikan motivasi dan penyuluhan akan pentingnya berwirasusaha. 
Program pengabdian ini disusun berdasarkan hasil survey pendahuluan oleh TIM PKM ke lokasi RT $006 \mathrm{Rw} 10 \mathrm{Kp}$. Cimuncang Desa karangnunggal, Kabupaten Tasikmalaya, Propinsi Jawa Barat serta wawancara kepada kepada masyarakat.

Berikut ini contoh pengolahan hasil pertanian dengan menggunakan teknologi mesin :

1. Pengolahan buah menjadi kripik buah

Ternyata buah yang nilai ekonomisnya tidak seberapa jika diolah dengan menggunakan vacum fyring bisa menjadi kripik buah yang nilai jualnya bisa 10 kali lipat dibandingkan dijual dalam keadaan segar. Banyak aneka buah yang bisa diolah menjadi keripik buah yang rasanya berbeda dan mempunyai daya tahan lebih lama jika pengemasannya dilakukan secara benar. Contoh buah yang bisa diolah menjadi keripik antara lain; Pisang, nanas, apel, nangka, manga, salak, dan lain - lain.

2. Pengolahan berbagai produk pertanian menjadi tepung misalnya jagung, singkong, beras, dan lain-lain. Di kampung Cimuncang desa Karangnunggal, mayoritas masyarakatnya bekerja sebagai petani, sehingga hasil padi melimpah.

3. Pengolahan keripik pisang dan singkong

Pengolahan biji kopi, juka diolah dengan menggunakan tehnologi dan pengolahan yang benar dan berbeda maka akan tercipta kopi dengan kualitas unggul.

4. Pengolahan jamu

Dengan aneka ragam tanaman jamu bisa diolah menjadi beberapa produk jamu yang bermanfaat untuk kesehatan yang akan dibutuhkan oleh masyarakat pada umumnya. Dan masih banyak lagi hasil pertanian dan cocok tanam yang bisa diolah agar mempunyai nilai lebih tentunya.

Dari permasalahan ini, kami tertarik melakukan PKM (pengabdian kepada masyarakat) di RT 006 RW 10 Kp Cimuncang Desa Karangnunggal Kabupaten Tasikmalaya Propinsi Jawa Barat karena beberapa hal yaitu sebagai berikut :

1. Pentingnya mental wirausaha yang baik untuk meningkatkan taraf hidup masyarakat RT 006 Rw 10 Kp. Cimuncang Desa Karangnunggal Kabupaten Tasikmalaya Propinsi Jawa Barat.

2. Kami bermaksud untuk memberikan penyuluhan mental wirausaha bagi masyarakat RT 006 Rw 10 Kp. Cimuncang Desa Karangnunggal Kabupaten Tasikmalaya Propinsi Jawa Barat. Mengingat potensi sumber daya manusia (SDM) yang dimiliki oleh masyarakat RT 006 Rw 10 Kp. Cimuncang Desa Karangnunggal Kabupaten Tasikmalaya Propinsi Jawa Barat dalam upaya untuk meningkatkan taraf hidup dan kesejahteraan masyarakat serta peningkatan pendapatan keluarga maka perlu kiranya dilakukan penyuluhan kewirausahaan.

3. Pentingnya mengenai bentuk usaha apa yang dapat dikembangkan oleh masyarakat RT 006 Rw 10 Kp. Cimuncang Desa Karangnunggal Kabupaten Tasikmalaya Propinsi Jawa Barat. Sehingga diharapkan mereka mengerti tentang pentingnya tentang penyuluhan agar dapat digunakan sebaik mungkin, baik bagi dirinya maupun bagi lingkungan masyarakat di sekitarnya. 


\section{KESIMPULAN DAN SARAN}

\section{Kesimpulan}

Masyarakat Desa Karang Nunggal Kampung Cimuncang Kabupaten Tasik Jawa Barat yang memulai usaha dan sudah memulai usaha di dalam menjalankan usaha harus mempersiapkan serta merencanakan usahanya. Agar dapat dikelola dengan baik demi kelangsungan ekonomi dan meningkatkan pendapatan masyarakat desa tersebut dan menggali potensi sumber daya manusia yang dimilikinya dengan jenjang Pendidikan dan pemanfaatan teknologi untuk memasarkan hasil dari usaha yang dikembangkan ditempat tersebut.

\section{Saran}

Masyarakat harus terus aktif mengikuti kegiatan pelatihan dan pengembangan terkait dengan usaha yang mereka jalankan dan terus membina hubungan kemitraan dengan usaha yang lebih besar lagi, untuk menimba ilmu pengetahuan seputar pengembangan usaha.

\section{Ucapan Terima Kasih}

Rasa syukur dan suka cita kamu haturkan kepada segenap pihak yang telah mensukseskan kegiatan PKM dengan judul "MEMBANGUN MENTAL WIRAUSAHA UNTUK MENINGKATKAN TARAF HIDUP MASYARAKAT RT O06 RW 10 KP CIMUNCANG DESA KARANGNUNGGAL KABUPATEN TASIKMALAYA PROPINSI JAWA BARAT" kepada:

1. Rektor Dr. H. Dayat Hidayat, M.M, Rektor Universitas Pamulang Tangerang Selatan Banten.

2. Dr. Ali Maddinsyah, S.E., M.M., selaku Ketua LPPM Universitas Pamulang Tangerang Selatan - Banten.

3. Dr. Kasmad, S.E., M.,M., selaku Ketua Program Studi Manajemen Universitas Pamulang Tangerang Selatan - Banten.

4. Dr. Udin Ahidin, S.E., M.M., C.M.A, Selaku Wakil Program Studi Manajemen Universitas Pamulang Tangerang Selatan - Banten.

5. Drs. Waluyo Jati, M.M., Selaku Sekretaris Program Studi Manajemen Universitas Pamulang Tangerang Selatan - Banten.

6. Bapak Suhendar, selaku Kepala Dusun Cimuncang, Desa Karangnunggal, Kab. Tasikmalaya, Propinsi Jawa Barat.

7. Warga masyarakat RT 006 RW 10 Kampung Cimuncang, Desa Karangnunggal, Kab. Tasikmalaya, Propinsi Jawa Barat.

8. Mahasiswa Universitas Pamulang yang juga ikut berkontribusi terhadap kelancaran kegiatan PKM.

\section{DAFTAR PUSTAKA}

Amri, Ulil. (2010). Motivasi Mahasiswa Aktif Didalam Organisasi Ekstrakulikuler. Tidak Terbit

Armstrong, Michael. (2003), How to be An Even Better Manager, Edt :Lyndon Saputra, Penerbit Binarupa Aksara, Batam. 
Buchari, Alma, (2009), Manajemen Pemasaran dan Pemasaran Jasa, Cetakan kedelapan, Bandung: Alfabeta

Daryanto. (2012). Sari Kuliah Manajemen Pemasaran (cetakan 2). Bandung: PT Sarana Tutorial Nurani Sejahtera.

Fahmi, Irham. (2013). Analisis Laporan Keuangan. Bandung: Alfabeta.

Hasibuan, Malayu S.P. (2016). Manajemen Sumber Daya Manusia. Edisi. Revisi. Jakarta: Penerbit PT Bumi Aksara

Hisrich, R \& Peter M. (2000). Entrepreneurship.Edisi Keempat. Singapore Mc Gran-Hill. Inc

Lambing, P. A \& Kuehl C. R. (2000). Entrepreneurship. Edisi Kedua. Edition New Jersey.Pretice Hall

Rachbini, D.J. (2001), Pengembangan Ekonomi \& Sumber Daya Manusia, Penerbit Grasindo , Jakarta.

Riyanti, Benedicta, Prihatin, Dwi. (2003). Kewirausahaan dari Sudut Pandang Psikologi Kepribadian. Grasindo. Jakarta

Riyanti, B Dwi. (2002), Kecendrungan Inovasi, Proceeding Temu Ilmiah APIO, Psikologi Unair.

Rusdiana, H.A. (2014). Kewirausahaan Teori dan Praktik, Cetakan ke 1. Bandung: Pustaka Setia

Saiman, Leonardus. (2014). Kewirausahaan: Teori, Praktik, dan Kasus-Kasus. Jakarta: Salemba Empat.

Siregar, Eveline, \& Nara, Hartini. (2014). Teori Belajar dan Pembelajaran, Cetakan ke 2. Bogor: Ghalia Indonesia

Slamet, F. dkk. (2014). Dasar-dasar Kewirausahaan: Teori dan Praktik. Jakarta: PT Indeks

Solihin, D. (2020), Pengaruh Kepercayaan Pelanggan dan Promosi Terhadap Keputusan Pembelian Konsumen Pada Online Shop Mikaylaku Dengan Minat Beli Sebagai Variabel Intervening. JURNAL MANDIRI: Ilmu Pengetahuan, Seni, dan Teknologi, Vol. 4, No. 1.

Solihin, D. (2020), Faktor-Faktor yang Mempengaruhi Kinerja Pemasaran Pada PT. Prima Ufuk Semesta Studi Pada Outlet Rekanan PT. Prima Ufuk Semesta di Wilayah JABODETABEK, Jurnal Semarak, Vol. 3 No.1.

Solihin, D., \& Wibawanto, E. (2020), Pengaruh Kualitas Pelayanan, Harga, Dan Promosi Terhadap Keputusan Pelanggan Dalam Memilih Klub Basket Satria Indonesia Tangerang Selatan, Jurnal Pemasaran Kompetitif, Vol. 3, No. 3.

Solihin, D. (2019), Pengaruh Current Ratio dan Debt to Equtity Ratio Terhadap Return on Asset (ROA) Pada PT. Kalbe Farma Tbk. Jurnal Kreatif, Vol. 7. No. 1.

Suryana. (2009). Kewirausahaan: Pedoman Praktis, Kiatdan Proses Menuju Sukses. Jakarta: Salemba Empat.

Uno B, Hamzah. (2008). Teori Motivasi dan Pengukurannya, Jakarta : Bumi. Aksara

Wibowo Agus. (2011). Pendidikan Kewirausahaan (Konsep dan Strategi). Yogyakarta: Pustaka Pelajar 
Wikanso. (2013). Pengaruh Pendidikan Kewirausahaan Terhadap Motivasi Berwirausaha Mahasiswa STKIP PGRI Ngawi. Jurnal Ilmiah STKIP PGRI Ngawi Media Prestasi, Vol. XI, No. 1.

Winarto V (2003), Entrepreneurship : Semangat untuk memberikan solusi bagai masyarakat, Artikel http;//www.e-psikologi.com/pengembangan/rls.htm, 30-01-2003 